\title{
Research on the Performance of Taiwan's Laptop Industry Supply Chain Management System
}

\author{
Chu Fang, Zhang Wenli, Song Qiping, Weiwei Tan \\ Dongguan Polytechnic
}

\begin{abstract}
In recent years, Taiwan's PC industry has been faced with unprecedented threats, such as the shortening of product life cycle, the continuous improvement of product processes to meet customer needs, and even the requirement to achieve $195 \%$ of the products to be shipped to users within five days" to guarantee to large foreign factories. After winning the order, global operations management emerges, which is mainly due to the high demand for global operational research and management and the high willingness of information technology. However, due to the high cost of system construction and maintenance, most of the electronic and information factories are located in China. Business is the main part. It is worth discussing whether the manufacturer is willing to pay high cost to build the system and what factors will affect the performance of the supply chain management system of the notebook computer industry in Taiwan, China.
\end{abstract}

Keywords-Key Performance Indicator (KPI); Supply Chain Management(SCM); Case study

\section{INTRODUCTION}

Based on the motivation of the above research, this paper takes the manufacturers of notebook computer industry in Taiwan as an example to explore the general situation of suppliers importing supply chain management information system[1].

what is the motivation of laptop manufacturers to import the system? how does the supply chain management information system fit itself with the internal and external connections of the company? what do members of the supply chain know about partnership? how is the trust among partners in the supply chain? what factors affect the performance of the supply chain management system of Taiwan laptop manufacturers?

Beamon (2016) argues that the rise in manufacturing costs, the shortening of product life cycle and the globalization of the market economy are responsible for the development of supply chain management. [5].

$\mathrm{Hu}$ Xiuwu (2016) believes that the rise of supply chain management mainly comes from: (1) global competition, (2) the awakening of customer awareness, (3) the popularization of process concepts, (4) the innovation of information technology, and (5) the rise of alliances [7]

\section{LITERATURE REVIEW}

\section{A. The benefits of EDI}

Charalambos (2015) pointed out that the main reason why small enterprises adopt EDI (Electronic Data Interchange, hereinafter referred to as EDI) is the external environmental pressure, especially the requirements of trading partners. [10]Therefore, when large enterprises implement EDI, they should ask some small manufacturers to join as much as possible. A small firm must join in order to maintain its competitive position and to continue its trade relationship with the big manufacturers. However, only when some small firms realize the benefits of EDI and their own sufficient resources, these firms will integrate EDI into their information systems[2]

Establishment of supply chain management system

Wang Jingyi (2016) pointed out that the factors contributing to the success of supply chain management are:

The consensus of the whole supply chain members and the support of business owners.

Good and effective supply chain management refers to the supply and demand can be fully integrated between upstream and downstream, that is, the supply side (Supplier) and the client (Client) in full series, so the import process is very complex and lengthy, so enterprise owners and senior managers must support and propose coordination strategies, commitment to input personnel and resources, in order to be effective. Constructing a complete supply chain system[3].

\section{B. Adjustment and training of employees in Enterprises}

Supply chain management must cooperate with the introduction of IT technology, foreseeable adjustments to existing employee attitudes, mentality adjustment and training, process must not affect the existing work and the existing organization and process challenges. Etc., these are the owners and project leaders must take into account.

\section{Project team}

The project team must be familiar with the process and specifications of the project manager, the integration of IT technical specifications clear information personnel, as well as familiar with software functions of the consultant, and then with the full-time staff of various departments with the full cooperation [4]. 


\section{RESEARCH METHODS}

\section{A. Circulation and integration of information,}

The members of the supply chain system must sign a written agreement before information can be circulated and shared on the basis of mutual trust.

\section{B. System analysis and process construction}

The operation flow pattern of supply chain among members must be planned and analyzed systematically in advance so that the data flow can be correctly and efficiently processed.

\section{Code of conduct for business transactions}

For the part of capital flow, the payment terms, payment mechanism and payment schedule should be clearly regulated in advance to facilitate the benign interaction between manufacturers[6].

\section{Evaluation of supply chain efficiency}

After the introduction of the supply chain, it may be due to the time limit of the previous manufacturer, personnel or software itself. This part should be coordinated with Collaboration to discuss, redesign, coordinate with the actual operation mode and information flow process, and make full use of the warning function provided by information or software, so that a project team can be formed to periodically evaluate and evaluate the information. To enhance the efficiency of supply chain and improve the operation mode.

\section{E. Messages synchronize with the supply chain}

In the operation of the whole supply chain system, correct synchronous information sharing and rapid response are absolutely necessary conditions.

\section{F. Research method}

Through the research purpose and related literature, the research framework is constructed. As shown in Figure 1, the main purpose of this study is to understand what factors will affect the performance of the supply chain management system of notebook computer manufacturers in Taiwan, China.

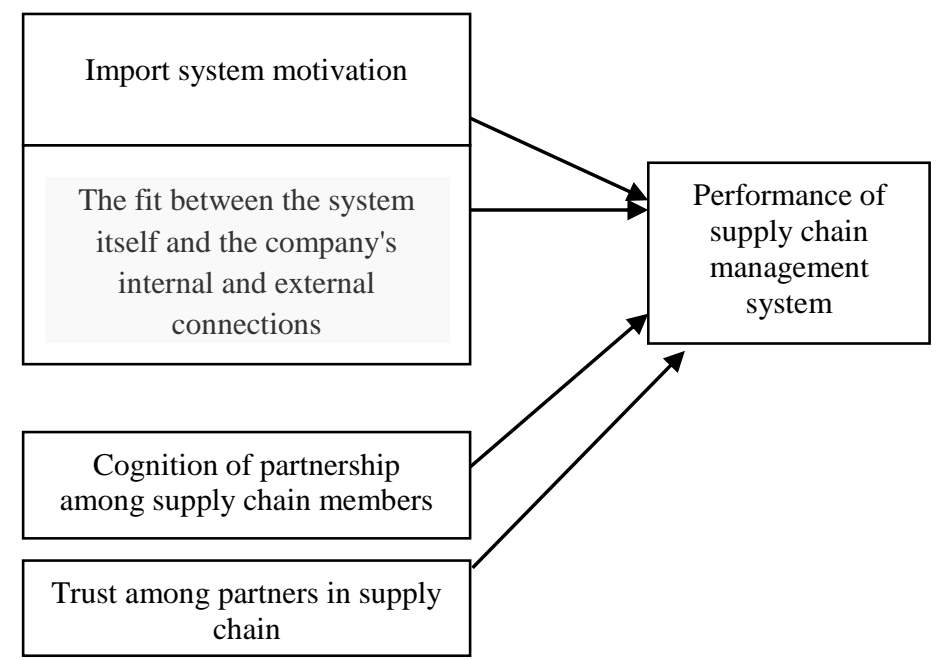

Fig. 1 Research objects and sampling design

(1) Source of research object: According to the manufacturer's register of Taiwan Computer Association, the IT IS manufacturer's database of China National Institute of Strategies and the related literature in the past, 11 first-line and second-line manufacturers in Taiwan's notebook computer industry were identified.

Front-line manufacturers: quanta, Ren Bao, Ying Da, Hua $\mathrm{Yu}$, Acer

Second line manufacturers: Volkswagen, Lun Fei, blue sky, Shenji, ASUS, and win.

(2) Sampling method: sampling method is mainly based on questionnaire survey. Questionnaire survey is conducted by email, mailed to the information department heads of the companies mainly, because by comparison, they are more familiar with the company's supply chain management system, ask them to fill in more reliable.

(3) Questionnaire design: This questionnaire is divided into four parts. The design of the questionnaire is based on the relevant literature to be revised. The first three questionnaires were composed of 44 questions. The Likert scale was used to measure the degree of agreement among notebook manufacturers. The degree of agreement was selected according to 1, 2, 3, 4 and 5. One was "very different". Two was "disagreement". Three was "no opinion". Four was "disagreement". Five was "very disagreement". The fourth part of the questionnaire is the company's basic information.

\section{G. Data analysis method}

This study uses SPSS statistical software package to analyze the collected data. In order to cooperate with this study, the following methods will be used to analyze the questionnaire data:

(1) Reliability analysis: Reliability analysis is mainly used to detect the consistency between items. Generally, Cronbach's alpha is used to measure the consistency between items under the same structure. Nunnally (2016) believed that if the reliability coefficient was above 0.7 , it would indicate high reliability, and the coefficient between 0.7 and 0.35 , indicating 
that the reliability is still acceptable. If the coefficient is below 0.35 , it would be expressed as low reliability and should be rejected.

(2) Factor analysis: Factor analysis is an interdependent analysis technique. Its main purpose is to represent the original data structure in fewer dimensions and to preserve most of the information provided by the original data structure (Huang Junying, 2016). The main purpose of this study is to extract the factors that affect the performance of the notebook computer supply chain management system[8].

(3) Correlation analysis: In this study, Pearson correlation coefficient was used to find out whether the variables are related, and then to understand the degree and direction of correlation.

(4) Regression analysis: Stepwise regression analysis is used to find out the factors that affect the performance of supply chain management system. By using this method, the variables with predictive ability can be found more accurately and the variables without predictive ability can be eliminated.

\section{H. Data analysis results}

First, reliability analysis.

Reliability analysis: Cooper and Emory (2015) considered that reliability refers to the degree of consistency and stability of measurement results. This study used Cronbach alpha to measure the reliability of each questionnaire. At the beginning, the Cronbach's alpha value of three facets was less than 0.7, that is to say, the reliability of each facet was not high. Therefore, factor analysis method was used to extract the main facets of this study [9].

(1) Two. Factor analysis, Factor analysis method adopts principal component analysis method in spindle method, and then orthogonal rotating shaft with maximum variation method. If the factor load is greater than 0.6 , it is defined as significant load, and according to this, the selected topic of each factor facet is determined, so as to facilitate the naming of common factors. According to this principle, this study can get eight factors, including 40 variables, and then analyze the reliability of each factor. The results are as follows: 1 .

TABLE I RELIABILITY TEST AND FACTOR ANALYSIS TABLE

\begin{tabular}{|c|c|c|}
\hline Names of variables and variables & Factor load & Cronbach's $\alpha$ \\
\hline $\begin{array}{l}\text { Coordination measures within the company } \\
\text { Q7 } \\
\text { Q30 } \\
\text { Q33 } \\
\text { Q34 } \\
\text { Q37 }\end{array}$ & $\begin{array}{l}0.604 \\
0.860 \\
0.856 \\
0.868 \\
0.777\end{array}$ & 0.8302 \\
\hline Motivation of introduction & & 0.7682 \\
\hline Q6 & 0.800 & \\
\hline $\begin{array}{l}\text { Q16 } \\
\text { Q21 } \\
\text { Q26 }\end{array}$ & $\begin{array}{l}0.803 \\
0.874 \\
0.611\end{array}$ & \\
\hline $\begin{array}{llll}\text { Consensus } & \text { coordination ancoordination among } \\
\text { Q3 } & & \\
\text { Q13 } & & \\
\text { Q27 } & & \\
\text { Q38 } & & \\
\end{array}$ & $\begin{array}{l}0.865 \\
0.759 \\
0.885 \\
0.828\end{array}$ & 0.8565 \\
\hline $\begin{array}{l}\text { Cognition agreement } \\
\text { Q8 } \\
\text { Q35 }\end{array}$ & $\begin{array}{l}0.834 \\
0.834\end{array}$ & 0.6818 \\
\hline $\begin{array}{l}\text { Trust among partners supply chain } \\
\text { Q4 } \\
\text { Q14 }\end{array}$ & $\begin{array}{l}0.985 \\
0.985\end{array}$ & 1.0 \\
\hline $\begin{array}{l}\text { Coordination partners } \\
\text { Q9 } \\
\text { Q19 } \\
\text { Q31 }\end{array}$ & $\begin{array}{l}0.852 \\
0.657 \\
0.809\end{array}$ & 0.7308 \\
\hline $\begin{array}{l}\text { Production sales performance } \\
\text { Q32 } \\
\text { Q36 } \\
\text { Q39 } \\
\text { Q40 } \\
\text { Q41 } \\
\text { Q42 } \\
\text { Q44 }\end{array}$ & $\begin{array}{l}0.851 \\
0.657 \\
0.933 \\
0.849 \\
0.634 \\
0.794 \\
0.585\end{array}$ & 0.8953 \\
\hline Order delivery performance & & 0.8593 \\
\hline
\end{tabular}




\begin{tabular}{|l|l|l|}
\hline & Table I, cont & \\
Q10 & 0.639 & \\
Q15 & 0.873 & \\
Q20 & 0.873 & \\
Q24 & 0.826 & \\
\hline
\end{tabular}

(2)Two. Factor analysis, Factor analysis method adopts This part discusses the correlation analysis of research variables, using Pearson correlation coefficient to find out whether the variables are related, and then to understand the degree and direction of the correlation. The results showed that $\mathrm{X} 1$ was significantly correlated with $\mathrm{X} 3, \mathrm{X} 6$ and $\mathrm{X} 9, \mathrm{X} 2$ was

significantly correlated with X13, and X5 was significantly correlated with X10, X6, X14, X9 and X15, as shown in Table

TABLE II CORRELATION ANALYSIS OF VARIABLES

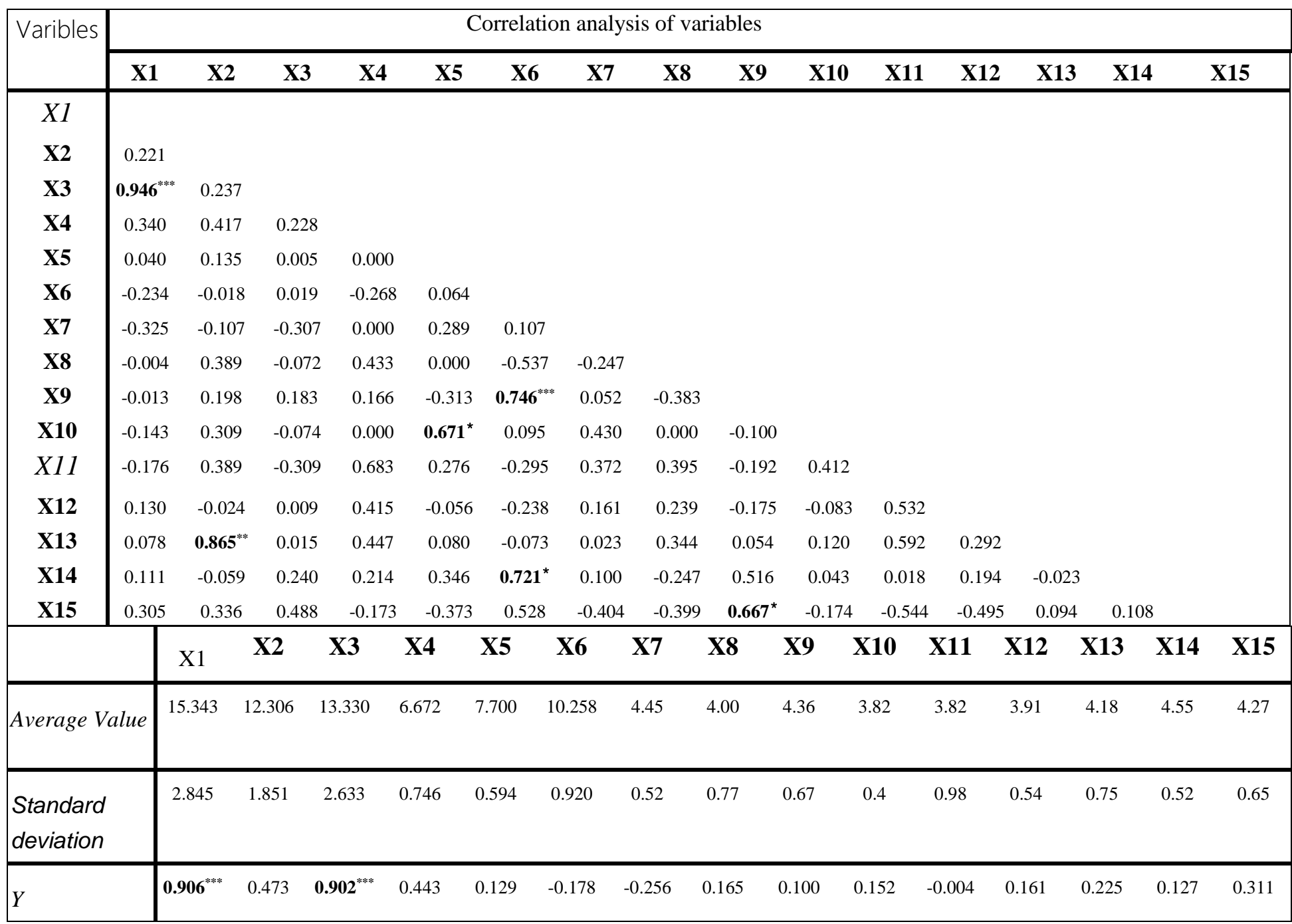


TABLE III REGRESSION ANALYSIS OF PERFORMANCE AND VARIABLES

\begin{tabular}{|c|c|c|c|c|}
\hline $\begin{array}{c}\text { Dependent variable } \\
\text { Variable }\end{array}$ & $\beta$ 值 & $\mathrm{t}$ 值 & R2 (modified) & $\mathrm{F}$ 值 \\
\hline $\begin{array}{c}\text { Total performance } \\
\text { X1 } \\
\text { X2 } \\
\text { X3 } \\
\text { X4 } \\
\text { X5 } \\
\text { X6 } \\
\text { X7 } \\
\text { X8 } \\
\text { X9 } \\
\text { X10 } \\
\text { X11 } \\
\text { X12 } \\
\text { X13 } \\
\text { X14 } \\
\text { X15 } \\
\end{array}$ & $\begin{array}{l}0.906 \\
0.287 \\
0.424 \\
0.152 \\
0.093 \\
0.037 \\
0.044 \\
0.169 \\
0.111 \\
0.288 \\
0.160 \\
0.044 \\
0.155 \\
0.026 \\
0.038 \\
\end{array}$ & $\begin{array}{c}6.419 * * * \\
2.497 * \\
0.967 \\
1.015 \\
0.639 \\
0.240 \\
0.277 \\
1.228 \\
0.770 \\
2.569 * \\
1.138 \\
0.290 \\
1.110 \\
0.173 \\
0.243 \\
\end{array}$ & 0.801 & $41.205^{* * *}$ \\
\hline $\begin{array}{c}\text { Company cooperation X3 } \\
\text { X6 }\end{array}$ & $\begin{array}{r}0.946 \\
-0.253 \\
\end{array}$ & $\begin{array}{l}8.794 * * * \\
-3.563 * * \\
\end{array}$ & 0.884 & $77.333 * * *$ \\
\hline Coordination team $\mathrm{X} 5$ & 0.671 & $2.714 *$ & 0.389 & $7.364^{*}$ \\
\hline Supply Chain Partner X9 & 0.746 & $3.357 * *$ & 0.507 & $11.273 * *$ \\
\hline
\end{tabular}

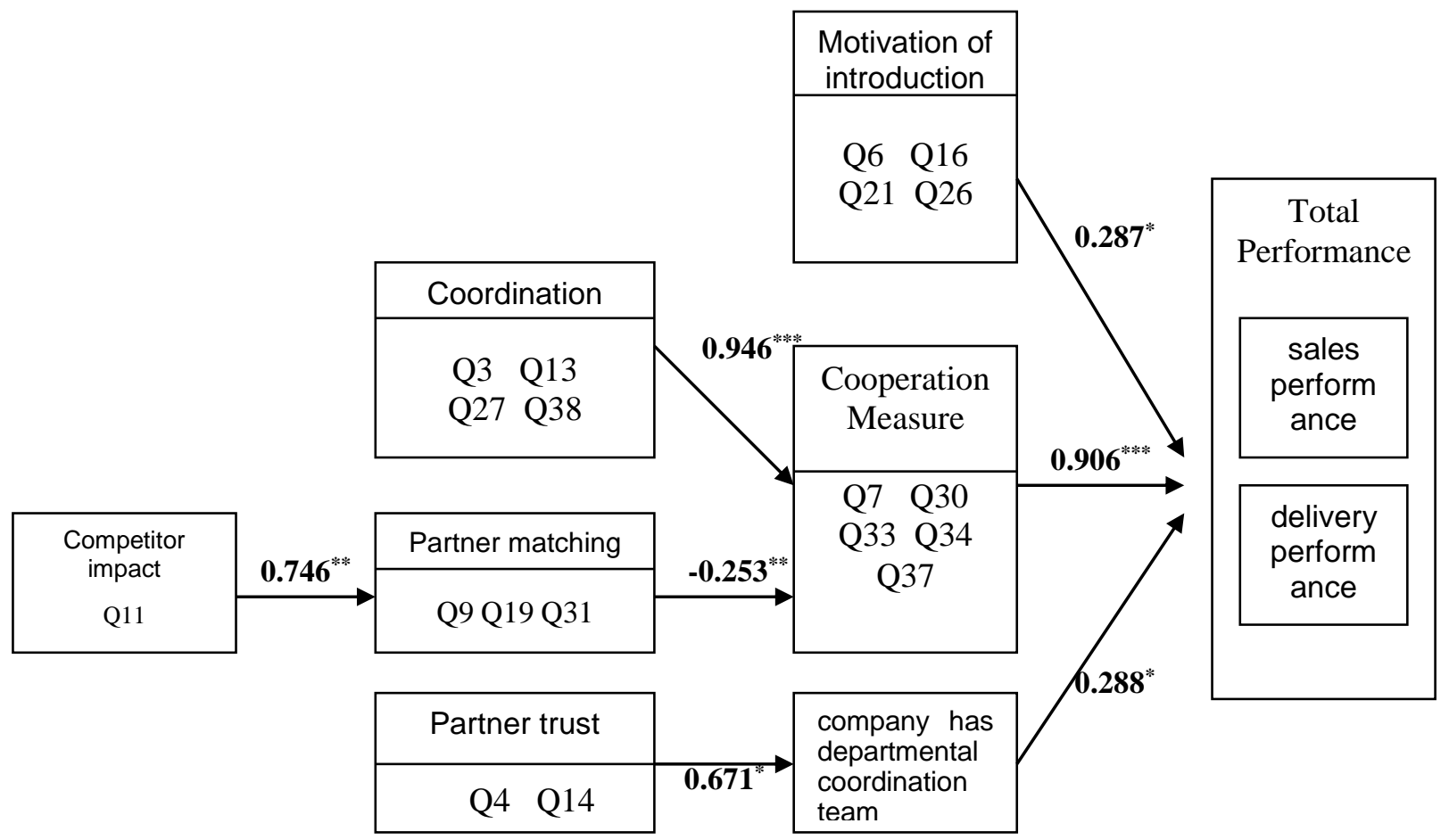

Fig. 2 Path analysis chart 


\section{CONCLUSIONS}

This study mainly explores what factors affect the performance of notebook PC manufacturers when they import SCM. After multiple regression analysis, a path analysis table is obtained. It is found that there are three factors affecting the overall performance, namely, the motivation of the import system, the internal co-ordination measures and the crossorganizational structure of the company. The "internal coordination measures" have the greatest impact on total performance. From this we can find that if senior managers can give support and support on resources and power, the internal process of the company has a certain degree of transparency, and for the establishment of supply management system to give appropriate education and training to employees, these coordinated measures will have a certain performance of supply chain management system. And it has positive effects.

In the aspect of "intra-company coordination measures", the analysis results show that the two factors are affected by "the degree of consensus and coordination among supply chain partners" and "the degree of coordination among supply chain partners". The results show that if the degree of consensus and coordination between supply chain partners is higher, the cooperation measures within the company will be better; and if the degree of coordination between supply chain partners is higher, the degree of coordination within the company will be lower, which can show that the company can not take both sides into account, if not taken into account the situation.

In terms of "the company has formed an inter-departmental coordination team", the analysis results show the reasons for the trust among supply chain partners.

As a result, if the company's suppliers are always able to deliver on time, and the supply chain partners are willing to share information, the trust between the supply chain partners will be stronger, and your company has a cross-enterprise team, and the willingness to discuss and solve problems regularly will be higher.

In the aspect of supply chain partnership coordination degree, the analysis results show that the factors affected by "the import system is affected by competitors". That is to say, if the company's import supply chain management system is more affected by competitors' pressure, the supply chain partners will be more able to cooperate with each other to compete with competitors.

\section{REFERENCES}

[1] Huang Junying, multivariate analysis, China Economic and Business Research Institute, 2015. (In Chinese)

[2] Guo Jiarong and $\mathrm{Li}$ Baiyi, Automation and Electronization of Information Industry in A.B Plan, Electronic Times, December, 1989. Business decision Forum] twenty-second, author: Wu Zhenming, Huang Qionghui. (In Chinese)

[3] Beamon, Benita M. "Supply Chain Design \& Analysis: Models \& Methods," International Journal of Production Economics, No.55, 2014, pp281-294.

[4] Christopher, M., "Logistics and Supply Chain Management," Pitman Publishing, 2008.

[5] Cooper, M.C., and Lisa M.E., "Characteristics of Supply Chain Management and Implication for Purchasing and Logistics Strategy," The International Journal of Logistics Management, Vol.4, No.2, 2013, pp16.

[6] Ellram, L.M., "A Managerial Guideline for the Development and Implement of Purchasing Partnerships", International Journal of Purchasing and Materials Management, Summer, 2016, pp.2-6.

[7] Kalakota, Ravi and Whinston, Andrew, "Frontiers of Electronic Commerce", 2016.

[8] Maloni, Ichael and Benton, W.C. "Supply chain partnerships: Opportunities for operations research", European Journal of Operational Research,101, 2017, pp.419-429.

[9] Nunnally, J.C., Psychometric theory, Mcgraw-Hill, New York, 2015.

[10] Walton, Lisa, "Partnership Satisfaction: Using The Underlying Dimensions of Supply Chain Partnership to Measure Current and Expected Levels of Satisfaction", Journal of Business Logistics, V17, N2,2016,pp.57-75. 